\title{
The Effects of Static and Dynamic Culture Systems on Cell Proliferation and Conditioned Media of Umbilical Cord-Derived Mesenchymal Stem Cells
}

\author{
Retno Wahyu Nurhayati ${ }^{1,2 *}$, Dinda Shezaria Hardy Lubis ${ }^{3}$, Gita Pratama ${ }^{4,5}$, Elizabeth \\ Agustina $^{4}$, Zakiyatul Khoiriyah², Kamila Alawiyah ${ }^{2,6}$, Jeanne Adiwinata Pawitan $2,5,7$ \\ ${ }^{1}$ Departement of Chemical Engineering, Faculty of Engineering, Universitas Indonesia, Kampus UI Depok, Depok \\ 16424, Indonesia \\ ${ }^{2}$ Stem Cells and Tissue Engineering Cluster, Indonesian Medical Education and Research Institute, Faculty of \\ Medicine, Universitas Indonesia, Kampus UI Salemba, Jakarta 10430, Indonesia \\ ${ }^{3}$ Department of Biology, Faculty of Mathematics dan Natural Sciences, Universitas Indonesia, Kampus UI Depok, \\ Depok 16424, Indonesia \\ ${ }^{4}$ Department of Obstetrics and Gynecology, Faculty of Medicine, Universitas Indonesia - Dr. Cipto Mangunkusumo \\ General Hospital (RSCM), Jl. Diponegoro No 71, Salemba, Jakarta Pusat 10430, Indonesia \\ 5 Integrated Service Unit of Stem Cell Medical Technology (IPT TK Sel Punca), Dr. Cipto Mangunkusumo General \\ Hospital (RSCM), Jl. Diponegoro No 71, Salemba, Jakarta Pusat 10430, Indonesia \\ ${ }^{6}$ Department of Anatomy, Faculty of Medicine, Universitas Indonesia, Kampus UI Salemba, Jakarta 10430, \\ Indonesia \\ ${ }^{7}$ Department of Histology, Faculty of Medicine, Universitas Indonesia, Kampus UI Salemba, Jakarta 10430, \\ Indonesia
}

\begin{abstract}
Preclinical and clinical studies have demonstrated the therapeutic effects of umbilical cord-derived mesenchymal stem cells (UC-MSCs) and secretome to cure various degenerative diseases. Thus, the mass-scale production of MSCs is necessary to ensure their availability and costeffectiveness. In the current study, we evaluated the effect of dynamic 3D and static 2D culture systems on cell proliferation and conditioned media of UC-MSCs. The lysate of concentrated thrombocyte was used to substitute animal-derived serum in the culture media. From two experimental sets with different UC and lysates of concentrated thrombocyte donors, it was found that the shortest PDTs for experimental set 1 were $12.3 \mathrm{~h}$ (2D culture) and $14.8 \mathrm{~h}$ (3D culture), whereas in experimental set 2 , they were $17.7 \mathrm{~h}$ (2D culture) and $16.9 \mathrm{~h}$ (3D culture). Microscopic observation confirmed the formation of cell aggregates in the 3D system, particularly during the exponential phase. SDS-PAGE analysis revealed similar protein profiles of conditioned media from both culture systems. An anti-inflammatory cytokine, namely tumor necrosis factor beta (TGF- $\beta$ ), was analyzed using ELISA to evaluate the effect of culturing methods on TGF- $\beta$ release. Interestingly, the relative TGF- $\beta$ contents in the $2 \mathrm{D}$ culture were stagnant throughout the incubation times, whereas a higher accumulation of TGF- $\beta$ was detected in the 3D culture, which was most likely caused by shear stress. Our study confirmed that a dynamic culture system with a microcarriersupported bioreactor is a promising approach to scaling up MSC and secretome productions.
\end{abstract}

Keywords: Bioreactor; Dynamic culture; Mesenchymal stem cells; Proliferation; Secretome

*Corresponding author's email: retno.wahyu01@ui.ac.id, Tel.: +62-21-7863516, Fax.: +62-21-7863515 doi: 10.14716/ijtech.v12i6.5172 


\section{Introduction}

Mesenchymal stem cells (MSCs) are multipotent cells that can differentiate into various types of adult cells, such as osteocytes, chondrocytes, adipocytes, and others (Jiang et al., 2002; Rizal et al., 2020). Preclinical and clinical studies have uncovered therapeutic effects of MSC therapy in curing various degenerative diseases (Parekkadan and Milwid, 2010). In addition to MSCs, secretome is a promising resource for regenerative medicine due to its rich supply of growth factors and cytokines (Pawitan et al., 2017). Secretome can be collected from the conditioned media as a product of MSC culture. MSC secretome contains various growth factors and cytokines, including Epidermal Growth Factor (EGF), Vascular Endothelial Growth Factor (VEFG), Nerve Growth Factor (NGF), and Placental Growth Factor (PIGF) (Pawitan et al., 2017). Other studies have suggested that MSCs from the umbilical cord also secrete transforming growth factor (TGF)- $\beta$ (Farias et al., 2018) that plays a direct role in cell growth, proliferation, differentiation, anti-inflammatory effects, immunomodulation, and wound healing (Phelps et al., 2018).

The immense potential of MSCs and secretome in therapeutic applications requires mass-scale production to ensure its availability and cost effectiveness. MSCs, similar to other stem cells, are limited in their native tissues; therefore, several methods have been developed for facilitating in vitro cell cultures. The conventional MSC culture uses 2dimensional (2D) surface-treated containers, such as a flask or dish, to facilitate cell attachment. Static 2D culture is feasible for small-scale MSC expansion; however, this method is costly and quite challenging to adopt for large-scale cell production (Mizukami et al., 2018). The 3D culture system is a promising method for scaling up cell production using various types of bioreactors (Tsai et al., 2019; Sibuea et al., 2020; Nadhif et al., 2020). Dissolved oxygen in conventional culture can be maintained by limiting media depth. Meanwhile, in a 3D culture system, the oxygen level can be improved via agitation or oxygen infusion, which may increase hydrodynamic stress for cells.

Our current study was designed to evaluate the effects of static $2 \mathrm{D}$ and dynamic $3 \mathrm{D}$ culture methods on the MSCs' proliferation and secretome profile. Lysed human thrombocyte/platelet concentrate was used to substitute for animal-derived serum. A stirred bioreactor was employed in this study due to its adequate capacity, ease of adjustment, homogeneous conditions, ease of scale-up, and ease of control (Mizukami et al, 2018). The TGF- $\beta$ level in conditioned media was measured to compare the effects of culturing methods to the specific cytokine release.

\section{Methods}

\subsection{MSC Isolation and Culture}

MSCs were isolated from umbilical cords (UC), as described elsewhere (Pawitan, 2014). Briefly, UCs from non-infectious subjects $(n=2)$ were soaked in povidone iodine solution for $10 \mathrm{~min}$ and washed three times with phosphate-buffered saline (PBS). The blood vessels were removed, and wharton jelly-rich tissue was placed in a multi-well plate. Complete media composed by alpha Minimum Essential Medium, 10\% lysed concentrated thrombocyte (Indonesian Red Cross, Indonesia), $2 \mathrm{mM}$ L-alanyl-L-glutamine dipeptide/Glutamax, Antibiotic-Antimycotic, and $10 \mathrm{U} / \mathrm{mL}$ heparin/Inviclot (Pratapa Nirmala, Indonesia). Culture media were changed every two to three days. Sprouting cells from explants were detached using an enzymatic method with TrypLE ${ }^{\mathrm{TM}}$ Select and seeded into a T-flask. The cells were passaged at least twice before being used for further experiments. Cell culture was conducted in a fully humidified $\mathrm{CO}_{2}$ incubator at $37^{\circ} \mathrm{C}$. As otherwise stated, all reagents for cell culture and chemicals were purchased from 
ThermoFisher Scientific (USA) and Merck (USA), respectively.

\subsection{MSCs Characterization}

The purity and stemness of MSCs were characterized via flow cytometry and trilineage differentiation, as described elsewhere (Dilogo et al., 2018). For surface marker analyses, the cultured cells were stained using a Human MSC Analysis Kit (BD Biosciences, USA), according to the manufacturer's protocol. The stained cells were then loaded in a flow cytometer (FACS AriaIII, BD Biosciences) to confirm the purity of CD73, CD90, and CD105 positive cells. For differentiation assays, the cells were cultured until reaching $80 \%$ confluency and then replaced with StemPro Chondrogenesis/Osteogenesis/Adipogenesis Differentiation Kits. The cells were incubated, as described above, and the differentiating media were replaced every 2-3 days. After 14-21 days, the differentiated cells were stained with $1 \%$ of alcian blue, $2 \%$ of alizarin red, and $1.4 \%$ oil red 0 for confirming the cell potencies in chondrogenesis, osteogenesis, and adipogenesis, respectively.

\subsection{Static $2 D$ and Dynamic 3D Cultures}

The 2D and 3D cultures were performed in a multi-well plate and spinner flask bioreactor with microcarriers, respectively (Figure 1). Collagen-coated microcarrier beads with a diameter of $125-212 \mu \mathrm{m}$ (assumption diameter average is $168.5 \mu \mathrm{m}$ ) were used to provide an attachment surface in a bioreactor system. Two independent experimental sets were conducted with different UC and lysates of concentrated thrombocyte donors. After confirming the MSC purity, the cells were seeded simultaneously in a multi-well plate or bioreactor with an initial density of $14 \times 10^{3}$ cells $/ \mathrm{cm}^{2}$. The initial medium depth in the well plates was kept at $0.22 \mathrm{~cm}$ to ensure gas exchange. The bioreactor cultures were carried out using 2 grams of microcarrier beads in $100 \mathrm{~mL}$ culture media. Seeding was conducted by mixing cells and microcarrier beads in half medium volume without agitation to facilitate cell attachment. After 16h, the medium was adjusted to $100 \mathrm{~mL}$, and the agitation was set at $50 \mathrm{rpm}$. A spinner flask neck was closed with a sterile filter of 0.22 micron (Sartorius Stedim Biotech, France) to allow gas exchange. Incubation of 2D and 3D cultures was conducted in a fully humidified $\mathrm{CO}_{2}$ incubator at $37^{\circ} \mathrm{C}$. The media in Experiment Set 1 was half exchanged on day 6, while the media in Experiment Set 2 was not exchanged.

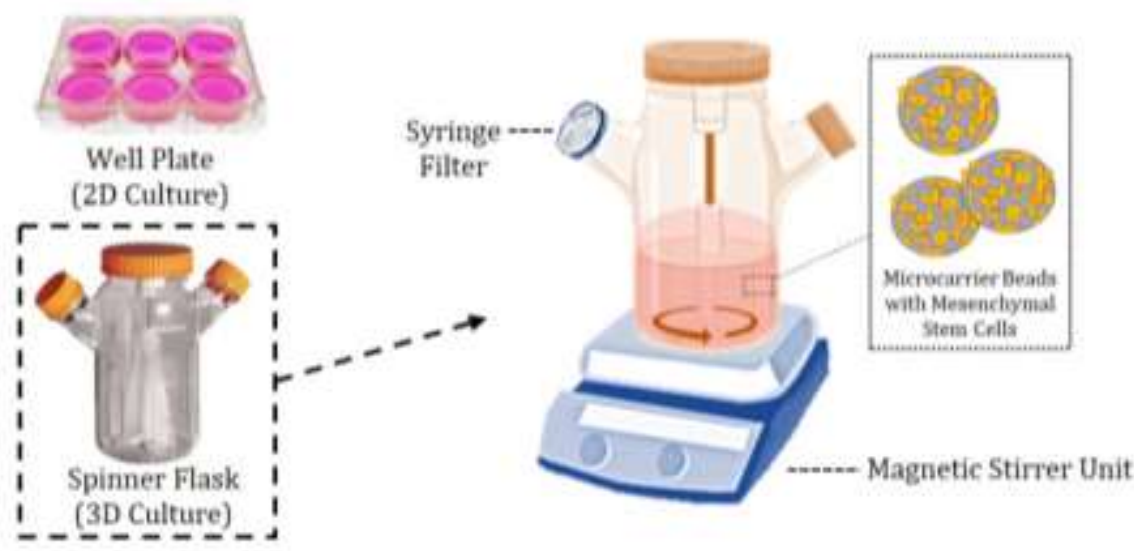

Figure 1 Umbilical cord mesenchymal stem cell (UCMSC) culture groups using static (2D) culture with 6-well plate and dynamic (3D) culture with spinner flask bioreactor and microcarrier beads

Cell counting was conducted daily by harvesting cells from wells or $1 \mathrm{~mL}$ media containing homogenous microcarriers $(n=3)$. Total and viable cell concentration were counted in a hemocytometer with tryphan blue to distinguish living and dead cells. Population doubling time (PDT) was calculated according to the following formula: 


$$
\mathrm{PDT}=\Delta t \times\left[\frac{\log 2}{\left(\log N_{t}-\log N_{t-1}\right)}\right]
$$

$\Delta \mathrm{t}$ is the incubation period ( $\mathrm{h}$ ), $\mathrm{N}_{\mathrm{t}}$ is the harvested cell concentration at $t$ (cells $/ \mathrm{mL}$ ), $\mathrm{N}_{\mathrm{t}-1}$ is the seeded cell concentration (cells/mL).

\subsection{Measurement of Total Protein Contents from Conditioned Media}

Conditioned media were collected prior to the cell detachment process. The total protein content from conditioned media was calculated via a Bradford Test with Bovine Serum Albumin (BSA) as a standard protein. In brief, a $5 \mu \mathrm{L}$ sample/BSA solution was mixed with a $200 \mu \mathrm{L}$ Bradford reagent and incubated at room temperature for 5 minutes. The absorbance was measured at $595 \mathrm{~nm}$ using a spectrophotometer (Shimadzu, Japan).

\subsection{Protein Detection using SDS-PAGE}

The protein expression in the conditioned medium was analyzed using the SDS-PAGE Mini-PROTEAN System (Atto, Japan). Samples of the conditioned medium from the 2D culture and 3D culture were mixed with a sample buffer $(1: 1)$ and boiled in water at $95^{\circ} \mathrm{C}$. A total of $5 \mu \mathrm{L}$ of protein markers and $20 \mu \mathrm{L}$ of samples were loaded into the well. Electrophoresis was set at $75-180 \mathrm{~V}$ for 75 to 80 minutes. The gel was rinsed with distilled water to remove the remaining SDS detergent and then immersed in a staining solution on an orbital shaker (RT; $50 \mathrm{rpm}$ ) for $60 \mathrm{~min}$. The gel was rinsed until it was clear with water and then washed 3 times every hour with a destaining solution to remove the dye. A protein ladder (PageRegulerTM Prestain Protein Ladder; ThermoFisher) was used to predict protein sizes (10 to $180 \mathrm{kDa}$ ).

\subsection{TGF- $\beta$ Measurement}

TGF- $\beta$ levels were measured with enzyme-linked immunosorbent assay (ELISA) according to the manufacturer's protocol (Elabscience, USA). The relative TGF- $\beta$ content (ng/ $\mu$ g protein) was calculated by dividing the cytokine concentration $(\mathrm{ng} / \mathrm{mL}$ ) by the total protein concentration $(\mu \mathrm{g} / \mathrm{mL})$ according to the following equation:

$$
\text { Relative TGF- } \beta \text { content }=\frac{[\text { TGF }-\beta]}{[\text { Total protein }]}
$$

\subsection{Statistical Analysis}

The data was analyzed using SPSS 22 software (IBM, USA). Comparison data from each experimental set between 2D and 3D cultures were analyzed using independent $t$-tests.

\section{Results and Discussion}

\subsection{UC-MSC Characteristics}

The MSC characteristics were assessed according to criteria from the International Society for Cellular Therapy (Dominici et al., 2006). The surface marker analyses with flow cytometry of cultured cells demonstrated that the cells expressed CD105 (98\%), CD73 $(100 \%)$, and CD90 (100\%), and almost none expressed hematopoietic markers (Lin- = $0.1 \%$ ) (Figure 2). In addition, the cells were able to differentiate into chondrogenic, osteogenic, and adipogenic lineages (Figure 3). These results confirmed the purity and stemness of isolated MSCs.

\subsection{Cell Proliferation in Static 2D and Dynamic 3D Cultures}

MSCs are anchorage-dependent cells that require suitable surfaces to facilitate cell attachment. Collagen-coated microcarriers were able to facilitate MSC attachment in a similar manner compared to those in a 2D culture system (Figure 4). 

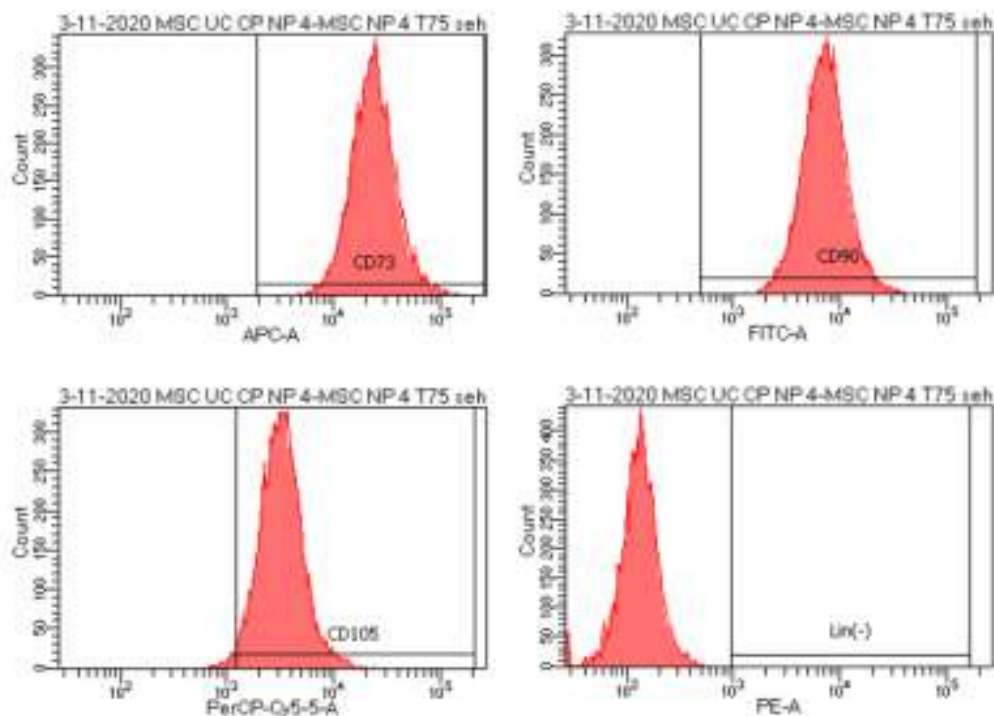

Figure 2 Histograms representative of MSC marker analyses with flow cytometer

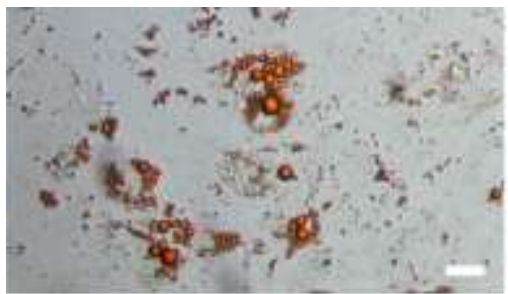

Adipogenesis

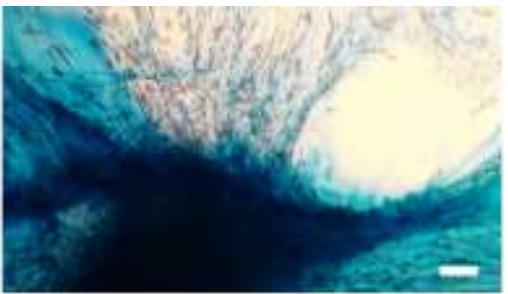

Chondrogenesis

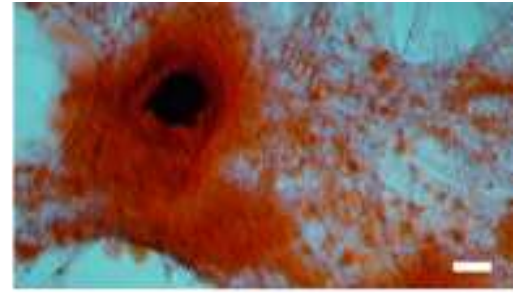

Osteogenesis

Figure 3 Trilineage differentiation assays. Scale bars represent $100 \mu \mathrm{m}$

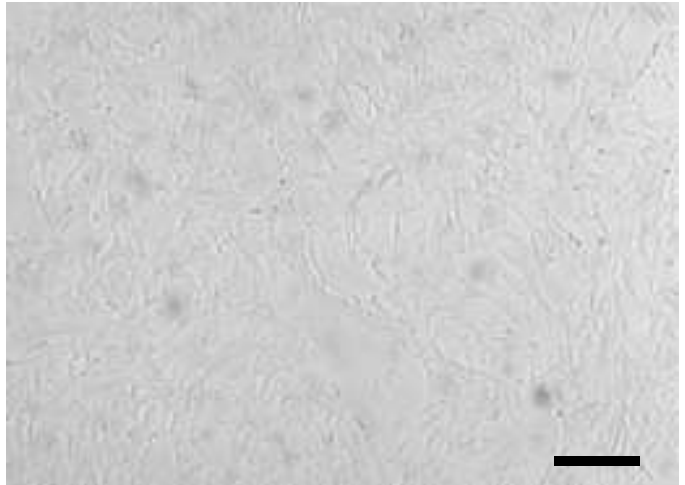

(a) 2D Culture

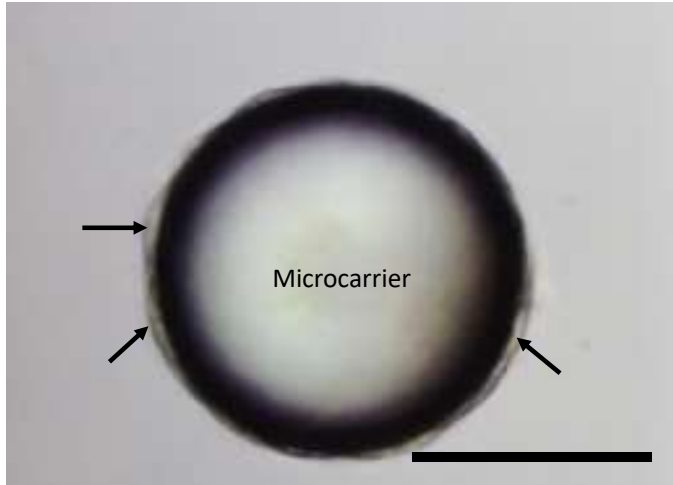

(b) 3D Culture

Figure 4 Microscopic images showing MSC attachment in 2D and 3D cultures. Scale bars represent $100 \mu \mathrm{m}$. Black arrows indicate adherent cells in microcarrier beads

Experimental sets 1 and 2, which used different resources, exhibited similar growth patterns except that the cell proliferation in set 2 was lower than in set 1 (Figure 5). A medium change exerted no effect on higher cell proliferation after day 5 . The 3D culture experienced a longer lag phase than the 2D culture. The 2D and 3D cultures underwent exponential growth on day 2 and 3, respectively, and both of the cultures reached the highest cell concentrations on day 5. The PDT was calculated based on Equation 1. The shortest PDTs for experimental set 1 were $12.3 \mathrm{~h}$ (2D culture) and $14.8 \mathrm{~h}$ (3D culture), whereas in experimental set 2 , they were $17.7 \mathrm{~h}$ (2D culture) and $16.9 \mathrm{~h}$ (3D culture). The 
quality of donors determines the quality of the mesenchymal stem cells. Mesenchymal stem cells may have different PDT rates and may experience aging in different ways (Paladino et al., 2016). Petry et al. (2018) proved that the differences in mesenchymal stem cell donors could affect the proliferation due to lifestyle, health, and other factors. In addition, different cell donors may cause different cell capacities to produce and tolerate metabolite waste, including lactate. Lactate is commonly accumulated under high cell density and limited oxygen transfer (Ouyang et al., 2007). The stirring factors cause cells to experience hydrodynamic stress (Bergemann et al., 2015; Nurhayati et al., 2018).

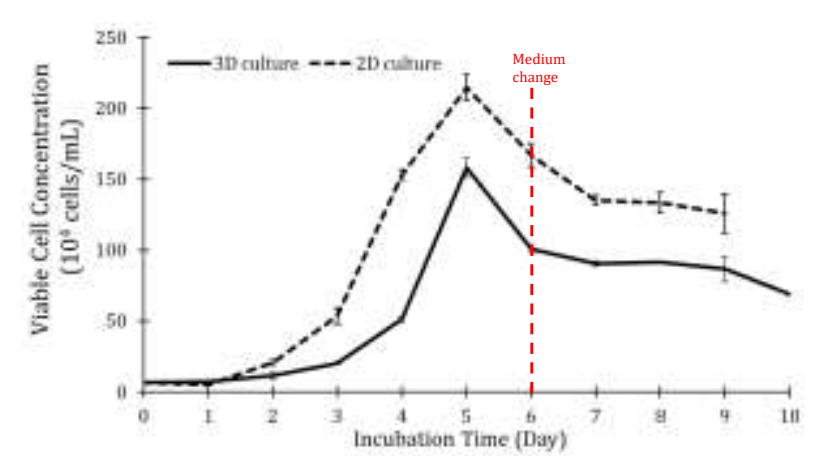

(a) Experiment Set 1

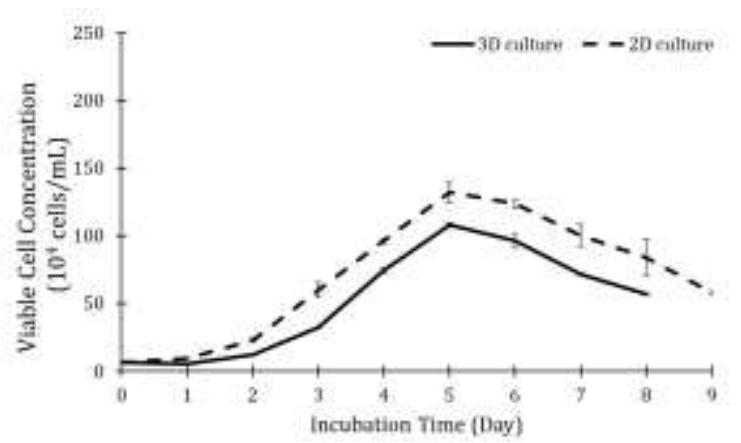

(b) Experiment Set 2

Figure 5 Viable cell concentration of MSCs cultured in static 2D culture and dynamic 3D culture. Cells and thrombocyte lysates used in experimental sets 1 and 2 were collected from different donors

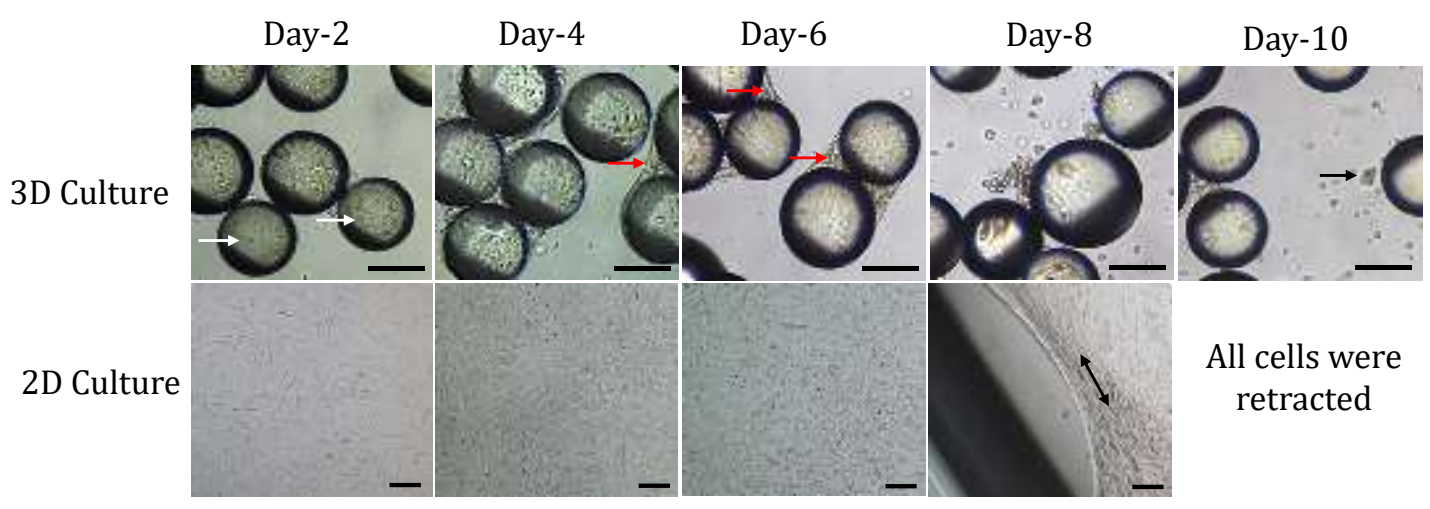

Figure 6 Representative microscopic images of MSCs in 2D and 3D cultures. White and red arrows indicate microcarrier beads and MSCs, respectively. Double-headed and black arrows indicate chondrocyte formation in 2D culture and cells that detached from the microcarrier beads, respectively. Scale bars represent $100 \mu \mathrm{m}$

As illustrated in Figure 6, the 2D culture using a multi-well plate on day 2 revealed that the cells were around 30\% confluent. On day 4 , the cells reached $70-80 \%$ confluency. The cells reached $90-100 \%$ confluency and formed the chondrocytes (retraction) on day 8. On day 10, all cells had retracted and differentiated into chondrocytes. The cells in 3D culture using a spinner flask were still adapting to the environment on day 2 due to the agitation factor (10-20\% confluent). The cells reached exponential growth (70-80\% confluent), and the cells were covering the surface of the microbeads on days 4-6. Cell-bead aggregates could be observed, particularly on day 6 post-seeding. On day 10 , the cells were $90-100 \%$ confluent, and some cells started to separate from the microbeads. The formation of cellbead aggregate is a major problem for microcarrier-supported cultures that eventually form dead-core due to a lack of oxygen/nutrient transport (Nurhayati et al., 2018). Our current study confirmed that a decrease in cell proliferation after day 5 was caused by cell- 
microcarrier aggregates rather than nutrient depletion or waste accumulation.

The 3D culture application allowed more efficient requirements in relation to the needs of the culture container and the composition of the medium (Das et al., 2019). The benefit of 3D culture application is a wider growth area, oxygen transfer, good nutrient distribution (Perez et al., 2014), and the provision of a homogeneous culture environment (Croughan et al., 2000). Although the live cell concentration in the 3D bioreactor culture was lower than in the 2D multi-well plate culture, the bioreactor system is a promising technology for largescale stem cells and secretome production, which could provide an autonomous and homogeneous culture system (Goh et al., 2013; Tsai et al., 2019).

\subsection{Total Protein Content of Conditioned Media}

The protein contents of conditioned media from 2D and 3D cultures fluctuated during the culture (Figure 7); this was affected by protein uptake and secretion (Vizoso et al., 2017).

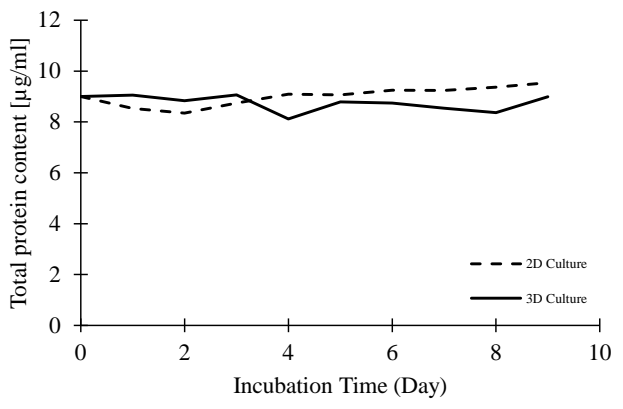

(a)

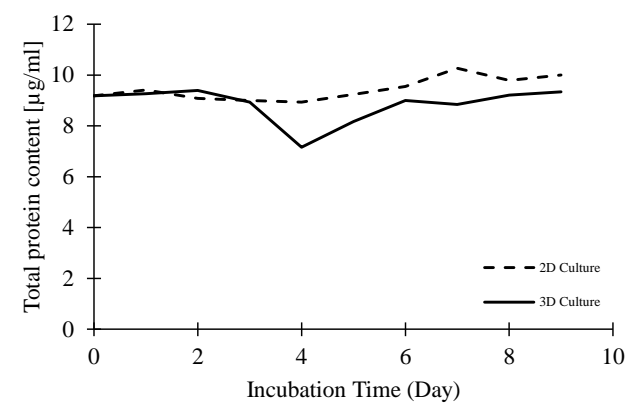

(b)

Figure 7 (a) Total protein content of conditioned media in experimental set 1 ; and (b) experimental set 2

After 3 days of incubation, it was noticed that media collected from 3D culture had lower protein contents than those from 2D culture. There was no significant temperature difference between both cultures; therefore, we hypothesized that hydrodynamic stress caused the increased protein uptake.

\subsection{Protein Separation with SDS-PAGE}

The protein from the conditioned media was separated based on its molecular weight with SDS PAGE. It was found that the protein patterns of conditioned media were similar, meaning that 3D and 2D cultures did not affect the secretion of major proteins. TGF- $\beta$ has a molecular weight of $25 \mathrm{kDa}$ (Herpin et al., 2004), and based on Figure 8, it was predicted
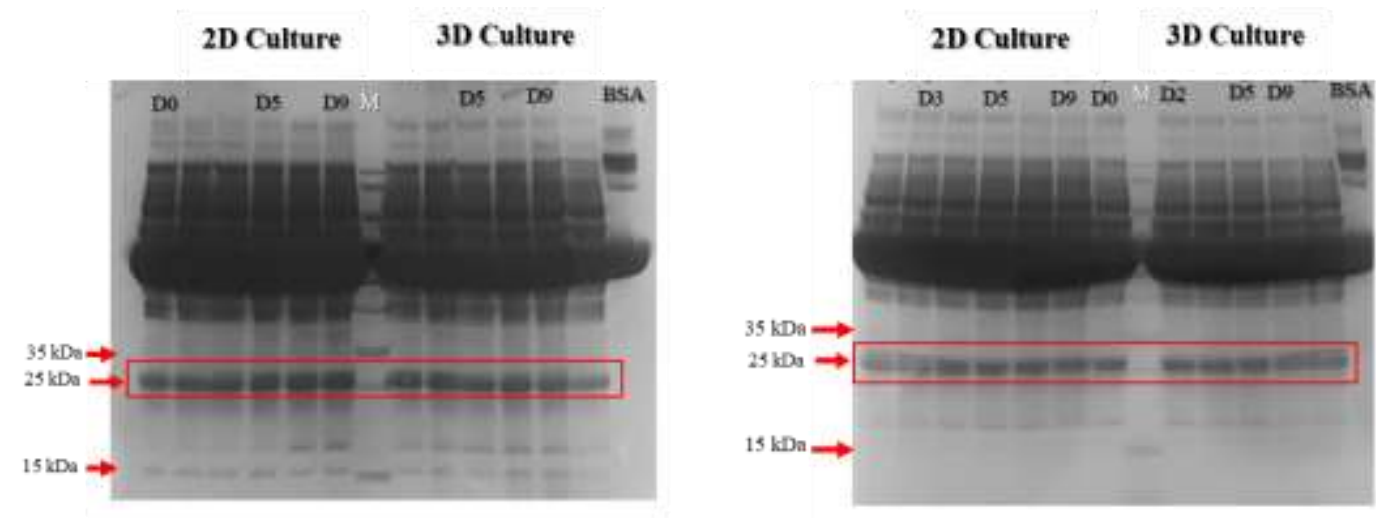

Figure 8 Representative image of the conditioned media's protein separation with SDS-PAGE. Protein marker (M) and bovine serum albumin (BSA) 
that the cytokine presented in culture media were derived from thrombocyte supplementation (Pavlovic et al., 2016) and/or MSCs secretion.

\subsection{Relative TGF- $\beta$ Contents in Conditioned Media}

TGF- $\beta$ plays an essential role in proliferation, growth, differentiation, apoptosis, and other cellular processes. The superfamily TGF- $\beta$ ligands bind to type II receptors, which phosphorylate the type I receptors. Type I receptors then phosphorylate receptorregulated SMADs (R-SMAD), which can bind to co-SMAD, namely SMAD4. The R-SMAD/coSMAD complex accumulates in the nucleus and will act as a transcription factor and participate in the regulation of target gene expression (Zhang et al., 2017).

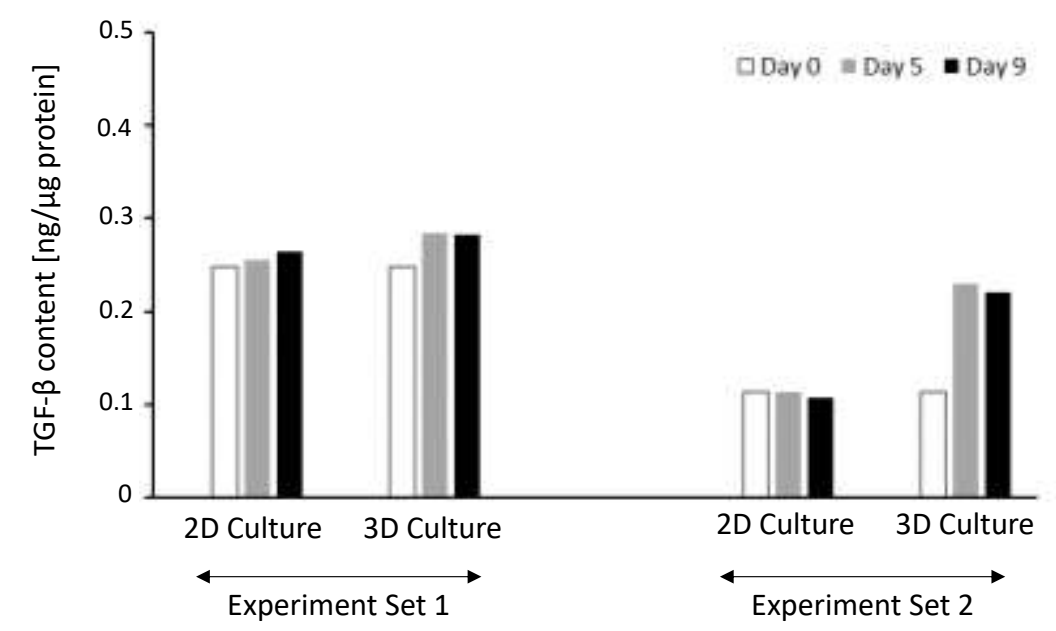

Figure 9 TGF- $\beta$ contents of conditioned media collected from 2D and 3D cultures $(n=2)$

TGF- $\beta$ measurements were conducted based on a spectrophotometric method and calculated based on Equation 2. It was confirmed that the cytokine existed in the fresh and spent media (Figure 9). Our study used the same batch of basal medium; therefore, the different relative TGF- $\beta$ contents of the fresh media were highly influenced by thrombocyte donors. Interestingly, it was noticed that the 3D bioreactor cultures generated higher levels of TGF- $\beta$ (Day 5,9$)$ than 2D multi-well plate culture. A previous study confirmed the TGF- $\beta$ secretion by MSCs in an animal serum-supplemented culture (Noh et al., 2016). Figure 9 illustrated that the relative cytokine contents in 2D cultures were stagnant throughout the incubation times, whereas the higher accumulation of TGF- $\beta$ was detected in the 3D culture. Although the MSC's proliferation and secretome production was donor-dependent (Beitzel et al., 2014), the dynamic culture affected the ability of MSCs to produce higher TGF- $\beta$ than the static culture. Although this has been studied for several decades, the exact regulation and production of TGF- $\beta$ is still under exploration. The TGF- $\beta$ complex has been recognized as a molecular sensor that responds to environmental disturbances to promote or inhibit cell proliferation. A recent study reported that shear stress induced by shaking the culture could up-regulate TGF- $\beta$ expression in immortalized human chondrocytes (Zhen et al., 2021). Consistent with our result, it appears that shear stress caused by dynamic 3D culture has the potential to increase TGF- $\beta$ production from MSCs.

\section{Conclusions}

UC-MSCs could grow effectively in thrombocyte-supplemented culture with dynamic 3D and static 2D systems. Based on two experimental sets with different UC and lysates of concentrated thrombocyte donors, it was found that the shortest PDTs for experimental set 1 were $12.3 \mathrm{~h}$ (2D culture) and $14.8 \mathrm{~h}$ (3D culture), whereas in experimental set 2 , they 
were $17.7 \mathrm{~h}$ (2D culture) and $16.9 \mathrm{~h}$ (3D culture). Microscopic observation suggested that cells formed aggregates in the 3D system, particularly after the cells reached the exponential phase. Decreased cell proliferation after day 5 was caused by cell-microcarrier aggregates rather than nutrient depletion or waste accumulation. The relative TGF- $\beta$ contents in the 2D culture were stagnant throughout the incubation process, whereas higher TGF- $\beta$ accumulation was detected in the 3D culture. Our study demonstrated that dynamic culture systems could improve specific cytokine production from UC-MSCs. Further research is necessary to elucidate the effects of hydrodynamic stress on cytokine production.

\section{Acknowledgements}

This work was supported by Q2 Scheme Research Grant (Hibah Publikasi Terindeks Internasional (PUTI Q2 2020)) No. NKB-1545/UN2.RST/HKP.05.00/2020 and IMERI research cluster grant 2018 (Hibah Klaster Riset IMERI 2018) from Universitas Indonesia.

\section{References}

Beitzel, K., McCarthy, M.B., Russell, R.P., Apostolakos, J., Cote, M.P., Mazzocca, A.D., 2014. Learning About PRP using Cell-based Models. Muscles, ligaments and tendons journal, Volume 4(1), pp. 38-45

Bergemann, C., Elter, P., Lange, R., Weismann, V., Hansmann, H., Klinkenberg, E.D., B, Nebe., 2015. Cellular Nutrition in Complex Three-Dimensional Scaffolds: A Comparison between Experiments and Computer Simulations. International Journal of Biomaterials, Volume 2015, pp. 1-12

Croughan, M.S., Hamel, J.F., Wang, D.I., 2000. Hydrodynamic Effects on Animal Cells Grown in Microcarrier Cultures. Biotechnology and Bioengineering, Volume 67(6), pp. 841-852

Das, R., Roosloot, R., van Pel, M., Schepers, K., Driessen, M., Fibbe, W.E., de Brujin, J.D., Roelofs, H., 2019. Preparing for Cell Culture Scale-Out: Establishing Parity of Bioreactor-and Flask-Expanded Mesenchymal Stromal Cell Cultures. Journal of Translational Medicine, Volume 17(1), pp. 1-13

Dilogo, I.H., Mujadid, F., Nurhayati, R.W., Kurniawan, A., 2018. Evaluation of Bone MarrowDerived Mesenchymal Stem Cell Quality from Patients with Congenital Pseudoarthrosis of the Tibia. Journal of Orthopaedic Surgery and Research, Volume 13(1), pp. 1-8

Dominici, M., le Blanc, K., Mueller, I., Slaper-Cortenbach, I., Marini, F.C., Krause, D.S., Deans, R.J., Keating, A., Prockop, D.J., Horwitz, E.M., 2006. Minimal Criteria for Defining Multipotent Mesenchymal Stromal Cells. The International Society for Cellular Therapy Position Statement. Cytotherapy, Volume 8(4), pp. 315-317

Farias, D.A.V., Carrillo-Gálvez, A.B., Martín, F., Anderson, P., 2018. TGF- $\beta$ and Mesenchymal Stromal Cells in Regenerative Medicine, Autoimmunity and Cancer. Cytokine \& Growth Factor Reviews, Volume 43, pp. 25-37

Goh, T.K.P., Zhang, Z.Y., Chen, A.K.L., Reuveny, S., Choolani, M., Chan, J.K.Y., 2013. Microcarrier Culture for Efficient Expansion and Osteogenic Differentiation of Human Fetal Mesenchymal Stem Cells. BioResearch Open Access, Volume 2(2), pp. 84-97

Herpin, A., Lelong, C., Favrel, P., 2004. Transforming Growth Factor- $\beta$-Related Proteins: An Ancestral and Widespread Superfamily of Cytokines in Metazoans. Developmental \& Comparative Immunology, Volume 28(5), pp. 461-485

Jiang, Y., Jahagirdar, B.N., Reinhardt, R.L., Schwartz, R.E., Keene, C.D., Ortiz-Gonzalez, X.R., Reyes, M., Lenvik, T., Lund, T., Blackstad, M., Du, J., Aldrich, S., Lisberg, A., Low, W.C., Largaespada, D.A., Verfaillie, C.M., 2002. Pluripotency of Mesenchymal Stem Cells 
Derived from Adult Marrow. Nature, Volume 418(6893), pp. 41-49

Mizukami, A., Chilima, T.D.P., Orellana, M.D., Neto, M.A., Covas, D.T., 2018. Technologies for Large-Scale Umbilical Cord-Derived MSC Expansion: Experimental Performance and Cost of Goods Analysis. Biochemical Engineering Journal, Volume 135, pp. 36-48

Nadhif, M.H., Assyarify, H., Waafi, A.K., Whulanza, Y., 2020. Reflecting on Mechanical Functionalities in Bioreactors for Tissue Engineering Purposes. International Journal of Technology. Volume 11(5), pp. 1066-1075

Noh, M.Y., Lim, S.M., Oh, K.W., Cho, K.A., Park, J., Kim, K.S., Lee, S.J., Kwon, M.N., Kim, S.H., 2016. Mesenchymal Stem Cells Modulate the Functional Properties of Microglia via TGF- $\beta$ Secretion. Stem Cells Translational Medicine, Volume 5(11), pp. 1538-1549

Nurhayati, R.W., Ojima, Y., Dohda, T., Kino-Oka, M., 2018. Large - Scale Culture of a Megakaryocytic Progenitor Cell Line with a Single-Use Bioreactor System. Biotechnology Progress, Volume 34(2), pp. 362-369

Ouyang, A., Ng, R., Yang, S.T., 2007. Long-Term Culturing of Undifferentiated Embryonic Stem Cells in Conditioned Media and Three - Dimensional Fibrous Matrices without Extracellular Matrix Coating. Stem Cells, Volume 25(2), pp. 447-454

Paladino, F.V., Peixoto-Cruz, J.S., Santacruz-Perez, C., Goldberg, A.C., 2016. Comparison Between Isolation Protocols Highlights Intrinsic Variability of Human Umbilical Cord Mesenchymal Cells. Cell and Tissue Banking, Volume 17(1), pp. 123-136

Parekkadan, B., Milwid, J.M., 2010. Mesenchymal Stem Cells as Therapeutics. Annual Review of Biomedical Engineering, Volume 15(12), pp. 87-117

Pavlovic, V., Ciric, M., Jovanovic, V., Stojanovic, P., 2016. Platelet Rich Plasma: A Short Overview of Certain Bioactive Components. Open Medicine, Volume 11(1), pp. 242-247

Pawitan, J.A., 2014. Prospect of Stem Cell Conditioned Medium in Regenerative Medicine. BioMed Research International, Volume 2014, pp. 1-14

Pawitan, J. A., Leviana, M., Sukmawati, D., Liem, I. K., Margiana, R., Tarcisia, T., 2017. Prospect of Umbilical Cord Mesenchymal Stem Cell Culture Waste in Regenerative Medicine. Journal of Global Pharma Technology, Volume 9(7), pp. 1-5

Perez, R.A., Riccardi, K., Altankov, G., Ginebra, M.P., 2014. Dynamic Cell Culture on Calcium Phosphate Microcarriers for Bone Tissue Engineering Applications. Journal of Tissue Engineering, Volume 5, pp. 1-10

Petry, F., Weidner, T., Czermak, P., Salzig, D., 2018. Three-Dimensional Bioreactor Technologies for the Cocultivation of Human Mesenchymal Stem/Stromal Cells and Beta Cells. Stem Cells International, Volume 2018, pp. 1-14

Phelps, J., Sanati-Nezhad, A., Ungrin, M., Duncan, N.A., Sen, A., 2018. Bioprocessing Of Mesenchymal Stem Cells and Their Derivatives: Toward Cell-Free Therapeutics. Stem Cells International, Volume 2018, pp. 1-23

Rizal, R., Syaidah, R., Evelyn, E., Hafizh, A., Frederich, J., 2020. Wharton's Jelly Mesenchymal Stem Cells: Differentiation Capacity Showing its Role in Bone Tissue Engineering. International Journal of Technology, Volume 11(5), pp. 1005-1014

Sibuea, C.V., Pawitan, J.A., Antarianto, R., Jasirwan, C.O.M., Sianipar, I.R., Luviah, E., Nurhayati, R.W., Mubarok, W., Mazfufah, N.F., 2020. 3D Co-Culture of Hepatocyte, a Hepatic Stellate Cell Line, and Stem Cells for Developing a Bioartificial Liver Prototype. International Journal of Technology, Volume 11(5), pp. 951-962

Tsai, H.H., Yang, K.C., Wu, M.H., Chen, J.C., Tseng, C.L., 2019. The Effects of Different Dynamic Culture Systems on Cell Proliferation and Osteogenic Differentiation in Human Mesenchymal Stem Cells. International Journal of Molecular Sciences, Volume 20(16), pp. 1-14

Vizoso, F.J., Eiro, N., Cid, S., Schneider, J., Perez-Fernandez, R., 2017. Mesenchymal Stem Cell 
Secretome: Toward Cell-Free Therapeutic Strategies in Regenerative Medicine. International Journal of Molecular Sciences, Volume 18(9), pp. 1-24

Zhang, Y., Alexander, P.B., Wang, X.F., 2017. TGF- $\beta$ Family Signaling in the Control of Cell Proliferation and Survival. Cold Spring Harbor Perspectives in Biology, Volume 9(4), pp. $1-22$

Zhen, G., Guo, Q., Li, Y., Wu, C., Zhu, S., Wang, R., Guo, X.E., Kim, B.C., Huang, J., Hu, Y., Dan, Y., Wan, M., Ha, T., An, S., Cao, X., 2021. Mechanical Stress Determines the Configuration of TGF $\beta$ Activation in Articular Cartilage. Nature Communication, Volume 12, pp. 1-16 